\title{
The Future of Luteal Phase Support in ART and the Role of Dydrogesterone
}

\author{
Panagiotis Drakopoulos ${ }^{1 *}$, Caroline Roelens ${ }^{1 \dagger}$, Michel De Vos ${ }^{1,2}$, Shari Mackens ${ }^{1}$, \\ AnnaLisa Racca ${ }^{1}$, Herman Tournaye ${ }^{1,2}$ and Christophe Blockeel ${ }^{1,3}$ \\ ${ }^{1}$ Center for Reproductive Medicine, Universitair Ziekenhuis Brussel, Vrije Universiteit Brussel, Brussels, Belgium, \\ ${ }^{2}$ Department of Obstetrics, Gynecology, Perinatology and Reproductology, Institute of Professional Education, Sechenov \\ University, Moscow, Russia, ${ }^{3}$ Department of Obstetrics and Gynaecology, University of Zagreb, Zagreb, Croatia
}

Keywords: luteal (phase) support, dydrogesterone, progesterone, endometrium, IVF

\section{INTRODUCTION}

In vitro fertilization (IVF) treatment routinely involves ovarian stimulation (OS) with gonadotropins in combination with GnRH analogs to prevent premature luteinization and ovulation (1). However, it is well-established that the use of GnRH analogs during OS may impair corpus luteum function, resulting in suboptimal endometrial receptivity (2). Thus, luteal phase support (LPS) with progestins is an essential part of IVF treatment and is mandatory to support implantation and to increase pregnancy rates after fresh embryo transfer (3).

Shevach Friedler,

Reviewed by:

Maria Costanza Chiti,

Cliniques Universitaire

Saint-LUC, Belgium

${ }^{*}$ Correspondence

Panagiotis Drakopoulos panagiotisdrakopoulos@hotmail.com

tThese authors have contributed equally to this work

Specialty section: This article was submitted to Assisted Reproduction, a section of the journal

Frontiers in Reproductive Health

Received: 18 October 2020 Accepted: 23 December 2020 Published: 20 January 2021

Citation: Drakopoulos P, Roelens C, De Vos $M$, Mackens S, Racca A, Tournaye $H$ and Blockeel C (2021) The Future of Luteal Phase Support in ART and the Role of

\section{TYPE OF PROGESTERONE AND ROUTE OF ADMINISTRATION}

Progestins can be administered using various routes, either vaginally, intramuscularly (IM), rectally, orally, or subcutaneously, with differential impact on the pharmacokinetics of progestins. Indeed, serum progesterone $(\mathrm{P})$ levels are higher when progestins are administered using the IM route compared to the vaginal one. On the other hand, although micronized P capsules had initially been developed for oral use, they can be administered vaginally, offering an effective alternative to oral and IM injections: serum P concentrations may be lower after vaginal compared to IM administration, but endometrial $\mathrm{P}$ levels are higher because of the uterine first pass effect, while several disadvantages of the IM route (i.e., injection site pain and discomfort, risk of infection) are avoided (4). On a similar note, vaginal micronized $\mathrm{P}$ is preferred over oral administration due to the rapid absorption and avoidance of the first-pass metabolism $(5,6)$. However, there are a number of downsides to the vaginal route of $\mathrm{P}$ administration, since vaginal irritation, discharge and bleeding may occur (7). Furthermore, suboptimal serum P levels in a subgroup of women who are prescribed vaginal $\mathrm{P}$ may be associated with reduced pregnancy rates (8). Therefore, vaginal micronized $\mathrm{P}$ administration should not be seen as a panacea.

In this regard, the concept of oral progestin administration in assisted reproduction technology (ART) has recently been revitalized, given that dydrogesterone (6-dehydro-retroprogesterone) has been extensively used for the treatment of other conditions associated with $\mathrm{P}$ deficiency since the 1960s (9). Dydrogesterone is a stereo-isomer of $\mathrm{P}$, with an additional double bond between carbons 6 and 7, characterized by a better oral bioavailability and higher specificity for $\mathrm{P}$ receptors compared with oral micronized $\mathrm{P}(10,11)$. A recent study demonstrated that after natural conception dydrogesterone supplementation from 6 to 20 weeks of gestation significantly reduced the incidence of preeclampsia (PE) in high-risk patients (12), while these findings were replicated by 
another retrospective study showing a reduction in $\mathrm{PE}$ rate after dydrogesterone supplementation in assisted reproductive techniques and intra-uterine insemination (13).

\section{Clinical Studies Evaluating Dydrogesterone in Fresh Cycle IVF}

Several small-scale clinical studies have shown that oral dydrogesterone is at least as efficacious as micronized vaginal progesterone in supporting pregnancy following fresh embryo transfer (14-16). These findings revived the interest in oral dydrogesterone for LPS and paved the way for large Phase III prospective RCTs (Lotus I and Lotus II studies), which led to the recent approval of oral dydrogesterone for LPS in IVF-ART.

In particular, Lotus I was an international Phase III noninferiority RCT including 1,034 patients undergoing IVF and fresh embryo transfer, which showed that dydrogesterone $30 \mathrm{mg}$ (10 mg three times daily) resulted in comparable ongoing pregnancy rates (pregnancy rates at 12 weeks of gestation of 37.6 and $33.1 \%$ in the oral dydrogesterone and micronized vaginal $\mathrm{P}$ group, respectively) compared to vaginal micronized P $600 \mathrm{mg}$ ( $200 \mathrm{mg}$ three times daily) (17). Similarly, Lotus II RCT compared oral dydrogesterone $30 \mathrm{mg}$ (10 mg three times daily) with $8 \%$ micronized vaginal $\mathrm{P}$ gel (90 mg once daily) and demonstrated noninferiority, with ongoing pregnancy rates at 12 weeks' gestation of $38.7 \%$ in the oral dydrogesterone group and $35.0 \%$ in the micronized vaginal progesterone gel group (18). The main conclusion of the two RCTs was that oral dydrogesterone is safe (no evidence for an increased risk for fetal malformation), well-tolerated and as efficient as vaginal $P$.

\section{Clinical Studies Evaluating Dydrogesterone in Frozen Embryo Transfer Cycles}

Frozen-thawed embryo transfer (FET) has become an increasingly important part of IVF treatment, with large clinical trials and meta-analyses demonstrating similar live birth rates to those associated with fresh embryo transfer (19). To date, several methods of endometrial preparation for FET have been developed, with hormone replacement therapy (HRT)-FET cycles being the most commonly used, in view of the reduced need for treatment monitoring and easier scheduling. In HRT-FET cycles estrogen and progesterone are administered consecutively, in order to mimic the endocrine conditions of the endometrium of a normal menstrual cycle. However, from an physiological point of view, LPS in HRT-FET is completely different compared to LPS in a fresh IVF cycle due to the lack of

TABLE 1 | Overview of evidence of dydrogesterone use in HRT-FET cycles.

\begin{tabular}{|c|c|c|c|c|c|}
\hline Study & $N$ & Study design & LPS in HRT-FET & Embryo stage & Outcome \\
\hline Zarei et al. (22) & 400 & $\mathrm{RCT}$ & $\begin{array}{c}400 \mathrm{mg} \text { MVP } 2 x / d \\
\text { vs. } \\
10 \mathrm{mg} \text { DYD } 2 x / d \\
\text { vs. } \\
10 \mathrm{mg} \text { DYD } 2 x / d+0.1 \mathrm{mg} \\
\text { GnRHa } \\
\text { vs. } \\
10 \mathrm{mg} \text { DYD } 2 x / \text { day }+ \\
1500 \text { IU hCG }\end{array}$ & Cleavage stage & $\begin{array}{c}\text { CPR } \\
\begin{array}{c}20,9,25, \text { and } 17 \%(p=0.03) \\
\text { OPR }\end{array} \\
\begin{array}{c}18,9,3, \text { and } 17 \%(p=0.07) \\
\text { MR }\end{array} \\
\begin{array}{c}18.1,35.7,14.8 \text {, and } 19.1 \%(p \\
=0.84)\end{array}\end{array}$ \\
\hline Alahmad et al. (24) & 314 & Retrospective & $\begin{array}{l}\text { MVP } 600 \mathrm{mg} / \text { day of } \\
90 \mathrm{mg} \\
\text { vs. } \\
\text { DYD } 10 \mathrm{mg} 3 x / \text { day }\end{array}$ & 2PN & $\begin{array}{c}\text { Cumulative CPR } \\
\text { Difference: } 1.4 \%, 95 \% \mathrm{Cl} \text { : } \\
\text { (-9.4 to } 12.6), p=0.80 \\
\text { CPR of first FET } \\
\text { Difference: }-3.2 \%, 95 \% \mathrm{Cl} \text { : } \\
\text { (-12.8 to } 7.4), p=0.54\end{array}$ \\
\hline Guo et al. (21) & 529 & Retrospective & $\begin{array}{c}\text { DYD } 10 \text { mg 4x/day } \\
\text { vs. } \\
\text { IM P4 } 60 \text { mg/day }\end{array}$ & $\begin{array}{c}\text { Cleavage } \\
\text { stage/blastocyst }\end{array}$ & $\begin{array}{c}\text { CPR } \\
\text { IR } \\
\text { MR } \\
\text { EPR } \\
\text { OPR } \\
\text { DR } \\
\text { no significant difference }\end{array}$ \\
\hline Rashidi et al. (23) & 180 & Pilot RCT & $\begin{array}{c}\text { IM P4 } 50 \text { mg 2x/d } \\
\text { vs. } \\
\text { DYD } 20 \mathrm{mg} 2 x / d \\
\text { vs. } \\
\text { MVP } 400 \mathrm{mg} 2 x / \mathrm{d}\end{array}$ & $\begin{array}{l}95 \% \text { cleavage } \\
\text { stage } \\
5 \% \text { blastcyst }\end{array}$ & $\begin{array}{c}\text { CPR } \\
\text { MR } \\
\text { LBR } \\
\text { no significant difference }\end{array}$ \\
\hline
\end{tabular}

LPS, luteal phase support; HRT, hormone replacement therapy; FET, frozen embryo transfer; RCT, randomized controlled trial; MVP, micronized vaginal progesterone, DYD,

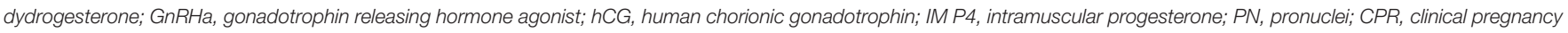
rate; OPR, ongoing pregnancy rate; $M R$, miscarriage rate; $I R$, implantation rate; $E P R$, ectopic pregnancy rate; $D R$, delivery rate; $L B R$, life birth rate. 
ovulation and absence of endogenous corpora lutea, suggesting that transformation of the endometrium into a receptive state for the implanting embryo is completely dependent on exogenous $\mathrm{P}$ supplementation (20).

While there is robust evidence demonstrating the efficacy of oral dydrogesterone for LPS in fresh IVF cycles as mentioned above, very few small studies using inconsistent doses have evaluated the role of dydrogesterone in HRTFET cycles [(21-24); Table 1]. In the only RCT performed up to date, Zarei et al. (22) reported lower pregnancy rates in the oral dydrogesterone group compared to the micronized vaginal $\mathrm{P}$ group, using doses of 20 and $800 \mathrm{mg}$, respectively. However, the lack of data with regard to the optimal dosing of oral dydrogesterone in FET-HRT, highlights the need for further studies. In view of the advancing understanding of the impact of an absent corpus luteum in FET-HRT cycles and the associated elevated risk for PE (25), dydrogesterone with its potential immunomodulatory effects (26) represents an interesting research track. Of great importance will be the development of a clinically applicable dose monitoring test for dydrogesterone and/or its metabolites, as an optimal LPS presumably lies in its individualization (8).

\section{REFERENCES}

1. Ovarian Stimulation T, Bosch E, Broer S, Griesinger G, Grynberg M, Humaidan P, et al. ESHRE guideline: ovarian stimulation for IVF/ICSI(dagger). Hum Reprod Open. (2020) 2020:hoaa009. doi: 10.1093/hropen/hoaa009

2. Beckers NG, Laven JS, Eijkemans MJ, Fauser BC. Follicular and luteal phase characteristics following early cessation of gonadotrophin-releasing hormone agonist during ovarian stimulation for in-vitro fertilization. Hum Reproduct. (2000) 15:43-9. doi: 10.1093/humrep/15.1.43

3. Delcour C, Robin G, Delesalle AS, Drumez E, Plouvier P, Dewailly D, et al. Weekly intramuscular progesterone for luteal phase support in women receiving oocyte donation is associated with a decreased miscarriage rate. Reproduct Biomed Online. (2019) 39:446-51. doi: 10.1016/j.rbmo.2019.05.001

4. Miles RA, Paulson RJ, Lobo RA, Press MF, Dahmoush L, Sauer MV. Pharmacokinetics and endometrial tissue levels of progesterone after administration by intramuscular and vaginal routes: a comparative study. Fertility Sterility. (1994) 62:485-90. doi: 10.1016/S0015-0282(16)56935-0

5. Bulletti C, de Ziegler D, Flamigni C, Giacomucci E, Polli V, Bolelli $\mathrm{G}$, et al. Targeted drug delivery in gynaecology: the first uterine pass effect. Hum Reproduct. (1997) 12:1073-9. doi: 10.1093/humrep/12. 5.1073

6. Cicinelli E, de Ziegler D. Transvaginal progesterone: evidence for a new functional 'portal system' flowing from the vagina to the uterus. Hum Reproduct Update. (1999) 5:365-72. doi: 10.1093/humupd/5.4.365

7. van der Linden M, Buckingham K, Farquhar C, Kremer JA, Metwally M. Luteal phase support for assisted reproduction cycles. Cochrane Database Syst Rev. (2015) 2015:CD009154. doi: 10.1002/14651858.CD009154.pub3

8. Labarta E, Mariani G, Holtmann N, Celada P, Remohi J, Bosch E. Low serum progesterone on the day of embryo transfer is associated with a diminished ongoing pregnancy rate in oocyte donation cycles after artificial endometrial preparation: a prospective study. Hum Reproduct. (2017) 32:2437-42. doi: 10.1093/humrep/dex316

9. Backer MH Jr. Isopregnenone (Duphaston): a new progestational agent. Obstet Gynecol. (1962). 19:724-9.

10. Schindler AE. Progestational effects of dydrogesterone in vitro, in vivo and on the human endometrium. Maturitas. (2009) 65(Suppl. 1):S3-11. doi: 10.1016/j.maturitas.2009.10.011

\section{CONCLUSION}

Collectively, there is evidence that dydrogesterone has high oral bioavailability and specificity for P receptors (27), suggesting that it is effective at a dose 10-20 times lower than that of micronized P (25). Dydrogesterone has a good safety and tolerability profile with few side effects, making the ideal candidate for LPS in ART. Oral dydrogestrone is as effective as vaginal progesterone for LPS in women undergoing fresh IVF, whilst more evidence is warranted for its use in HRT cycles. The well-known widespread preference of women for an oral compound may pave the way for dydrogesterone to become the new standard. Furthermore, preliminary observations showing a decreased risk of PE after dydrogesterone supplementation in natural and intrauterine insemination cycles $(12,13)$ may be of paramount value in HRTFET cycles, which are known to have a higher incidence of PE (28).

\section{AUTHOR CONTRIBUTIONS}

All authors contributed to this work and approved the final version.

11. Rizner TL, Brozic P, Doucette C, Turek-Etienne T, Muller-Vieira U, Sonneveld E, et al. Selectivity and potency of the retroprogesterone dydrogesterone in vitro. Steroids. (2011) 76:607-15. doi: 10.1016/j.steroids.2011.02.043

12. Tskhay V, Schindler A, Shestakova M, Klimova O, Narkevich capital A C. The role of progestogen supplementation (dydrogesterone) in the prevention of preeclampsia. Gynecol. Endocrinol. (2020) 36:698-701. doi: 10.1080/09513590.2019.1706085

13. Ali AB, Ahmad MF, Kwang NB, Shan LP, Shafie NM, Omar MH Dydrogesterone support following assisted reproductive technique (ART) reduces the risk of pre-eclampsia. Horm Mol Biol Clin Investig. (2016) 27:93-6. doi: 10.1515/hmbci-2015-0063

14. Ganesh A, Chakravorty N, Mukherjee R, Goswami S, Chaudhury K, Chakravarty B. Comparison of oral dydrogestrone with progesterone gel and micronized progesterone for luteal support in 1,373 women undergoing in vitro fertilization: a randomized clinical study. Fertility Sterility. (2011) 95:1961-5. doi: 10.1016/j.fertnstert.2011.01.148

15. Chakravarty BN, Shirazee HH, Dam P, Goswami SK, Chatterjee R, Ghosh S. Oral dydrogesterone vs. intravaginal micronised progesterone as luteal phase support in assisted reproductive technology (ART) cycles: results of a randomised study. J Steroid Biochem Mol Biol. (2005) 97:416-20. doi: 10.1016/j.jsbmb.2005.08.012

16. Tomic V, Tomic J, Klaic DZ, Kasum M, Kuna K. Oral dydrogesterone vs. vaginal progesterone gel in the luteal phase support: randomized controlled trial. Eur J Obstetr Gynecol Reproduct Biol. (2015) 186:49-53. doi: 10.1016/j.ejogrb.2014.11.002

17. Tournaye H, Sukhikh GT, Kahler E, Griesinger G. A phase III randomized controlled trial comparing the efficacy, safety and tolerability of oral dydrogesterone vs. micronized vaginal progesterone for luteal support in in vitro fertilization. Hum Reproduct. (2017) 32:2152. doi: 10.1093/humrep/dex266

18. Griesinger G, Blockeel C, Sukhikh GT, Patki A, Dhorepatil B, Yang DZ, et al. Oral dydrogesterone vs. intravaginal micronized progesterone gel for luteal phase support in IVF: a randomized clinical trial. Hum Reproduct. (2018) 33:2212-21. doi: 10.1093/humrep/dey306

19. Roque M, Haahr T, Geber S, Esteves SC, Humaidan P. Fresh vs. elective frozen embryo transfer in IVF/ICSI cycles: a systematic review and metaanalysis of reproductive outcomes. Hum Reproduct Update. (2019) 25:2-14. doi: 10.1093/humupd/dmy033 
20. Ghobara T, Gelbaya TA, Ayeleke RO. Cycle regimens for frozenthawed embryo transfer. Cochrane Database Syst Rev. (2017) 7:CD003414. doi: 10.1002/14651858.CD003414.pub3

21. Guo W, Chen X, Ye D, He Y, Li P, Niu J, et al. [Effects of oral dydrogesterone on clinical outcomes of frozen-thawed embryo transfer cycles]. Nan Fang Yi Ke Da Xue Xue Bao. (2013) 33:861-5.

22. Zarei A, Sohail P, Parsanezhad ME, Alborzi S, Samsami A, Azizi M. Comparison of four protocols for luteal phase support in frozen-thawed Embryo transfer cycles: a randomized clinical trial. Arch Gynecol Obstet. (2017) 295:239-46. doi: 10.1007/s00404-016-4217-4

23. Rashidi B, Ghazizadeh M, Tehrani Nejad E, Bagheri M, Gorginzadeh M. Oral dydrogesterone for luteal support in frozen-thawed embryo transfer artificial cycles: a pilot randomized controlled trial. Asian Pacific J Reproduct. (2016) 5:490-4. doi: 10.1016/j.apjr.2016.10.002

24. Alahmad A, Neumann K, Depenbusch M, Schultze-Mosgau A, OsterholzZaleski T, Hajek J, et al. Oral dydrogesterone vs. micronized vaginal progesterone for artificial frozen-thawed embryo transfer cycles. Hum Reproduct. (2019) 34:i442.

25. Schindler AE, Campagnoli C, Druckmann R, Huber J, Pasqualini JR, Schweppe KW, et al. Classification and pharmacology of progestins. Maturitas. (2003) 46(Suppl. 1):S7-16. doi: 10.1016/j.maturitas.2003.09.014

26. Griesinger G, Tournaye H, Macklon N, Petraglia F, Arck P, Blockeel C, et al. Dydrogesterone: pharmacological profile and mechanism of action as luteal phase support in assisted reproduction. Reproduct Biomed Online. (2019) 38:249-59. doi: 10.1016/j.rbmo.2018.11.017

27. Stanczyk FZ, Hapgood JP, Winer S, Mishell DR Jr. Progestogens used in postmenopausal hormone therapy: differences in their pharmacological properties, intracellular actions, and clinical effects. Endocr Rev. (2013). 34:171-208. doi: 10.1210/er.2012-1008

28. von Versen-Hoynck F, Schaub AM, Chi YY, Chiu KH, Liu J, Lingis $\mathrm{M}$, et al. Increased preeclampsia risk and reduced aortic compliance with in vitro fertilization cycles in the absence of a corpus luteum. Hypertension. (2019) 73:640-9. doi: 10.1161/HYPERTENSIONAHA.118. 12043

Conflict of Interest: The authors declare that the research was conducted in the absence of any commercial or financial relationships that could be construed as a potential conflict of interest.

Copyright (C) 2021 Drakopoulos, Roelens, De Vos, Mackens, Racca, Tournaye and Blockeel. This is an open-access article distributed under the terms of the Creative Commons Attribution License (CC BY). The use, distribution or reproduction in other forums is permitted, provided the original author(s) and the copyright owner(s) are credited and that the original publication in this journal is cited, in accordance with accepted academic practice. No use, distribution or reproduction is permitted which does not comply with these terms. 